\title{
Aproximaciones ideológicas a la reforma constitucional de 1910 en Colombia*
}

\author{
Ideological Approaches to the 1910 \\ Constitutional Reform in Colombia
}

James Iván Coral Lucero**

Recibido: 9 de octubre de 2015

Aprobado: 9 de febrero de 2016

Disponible en línea: 20 de diciembre de 2016

\section{Resumen}

El objetivo del artículo es hacer un análisis de las diferentes ideologías que dieron origen a la reforma constitucional de 1910 en Colombia y determinar cuáles fueron los principales cambios que se presentaron frente a la Constitución de 1886, tanto en su parte orgánica como dogmática. Con el fin hacer un estudio de los cambios en la parte orgánica, se tomaron como referencia tres temas sobre los cuales hubo un mayor debate durante la Asamblea Constituyente, estos son: facultades del presidente de la república, independencia judicial y organización territorial. Por su parte, los temas sobre los cambios en la parte dogmática giran en torno a la ampliación de derechos civiles y la prohibición de la pena de muerte. La metodología utilizada es el estudio de la influencia de las ideologías en los cambios que se mencionaron y la comparación detallada de los textos constitucionales. El resultado de la investigación demuestra que hubo un

\section{Abstract}

The aim of this text is to analyze the different ideologies that gave birth to the 1910 constitutional reform in Colombia, and pointing the main changes that arose in contrast to the Constitution of 1886, bot in its organic and dogmatic part. For the purpose of studying the changes in the organic part, I took as reference three topics on which there was major debate during the National Constitutional Assembly: powers of the president, judicial independence and territorial organization. On its part, changes in the dogmatic part are related to the broadening of civil laws and prohibiting death penalty. The methodology used is the study of the influence of ideologies on the changes mentioned above, as well as the comparison of constitutional texts. The result shows that there was a change of ideology and with it a return to a broader democracy in an institutional sense, as well as a greater respect for citizen and civil rights. The contribution of

doi:10.11144/Javeriana.papo21-2.airc

* Artículo de reflexión.

** Universidad de los Andes (Bogotá, Colombia). Correo electrónico: ji.coral10@uniandes.edu.co 
cambio de ideología y con este una vuelta hacia la restitución de una democracia más amplia en un sentido institucional, así como un mayor respeto por los derechos ciudadanos y civiles. El aporte del artículo es mostrar que la reforma de 1910 cambió la visión que tenía la Constitución de 1886 y abrió varios canales democráticos.

\section{Palabras clave}

reforma constitucional 1910; Constitución

de 1886; ideologías, cambios institucionales; derechos civiles

\section{Cómo citar este artículo:}

Coral-Lucero, J. I. (2016). Aproximaciones ideológicas a la reforma constitucional de 1910. Papel Político, 21(2), 373-393. https://doi. org/10.11144/Javeriana.papo21-2.airc the article is to show that the reform of 1910 changed the vision of the Constitution of 1886 and opened several democratic channels.

\section{Keywords}

1910 constitutional reform; 1886 constitution; ideologies; institutional changes; civil rights 


\section{A manera de introducción: delimitación de conceptos y algunas aproximaciones metodológicas}

La reforma constitucional de 1910 puede considerarse una de las más importantes del siglo XX, debido al espacio democrático que logró ofrecer para un periodo bastante crítico de la vida política colombiana, pues, tras la imposición de la Constitución de 1886 como una verdadera carta de batalla (Valencia, 2010), la reforma de 1910 parece implicar un rompimiento de aquel esquema. En este sentido, lo que se pretende demostrar es que el Acto Legislativo 03 de 1910 constituye un acuerdo o consenso constitucional en el que se consiguió un periodo de paz relativo, en oposición a la guerra y la exclusión de partidos que se venían imponiendo como una constante en Colombia.

Para el desarrollo de este artículo, se propondrán algunas aproximaciones conceptuales, con el fin de dar cuenta de los avances que la reforma de 1910 contenía. Con el objetivo de delimitar el marco analítico, se tomará como base la teoría de John Rawls sobre "consensos constitucionales". Dentro de esta teoría, se diferencian dos clases de consensos: el primero es un consenso constitucional en sentido formal y el segundo un consenso entrecruzado o traslapado (overlapping consensus) que sugiere la eficacia normativa. El consenso constitucional es, según Rawls,

la primera etapa, donde la Constitución satisface ciertos principios liberales de la justicia política, basados en un consenso constitucional, esos principios son aceptados, simplemente como principios, y no se fundan en determinadas ideas de la sociedad y de la persona de una concepción política. (2006, p. 191)

El consenso entrecruzado, por su parte, es más amplio, ya que no solo tiene que ver con los principios meramente políticos, sino subjetivos. De esta manera, una vez se ha logrado el consenso constitucional, los grupos políticos tienen que entrar en el foro público de la discusión política y enfrentarse a tesis que no comparten. Los consensos implican tanto ganancias o pérdidas para una postura ideológica u otra. Por tanto, en este estudio, se pretende observar qué tanto ganó o perdió una postura ideológica con el tránsito de la Constitución de 1886 a la reforma propuesta por el Acto Legislativo 03 de 1910.

El estudio se concentrará tanto en la parte orgánica de la Constitución, es decir, el análisis de los cambios que se pudieron presentar en el orden institucional, como en la parte dogmática, donde se pretende determinar cuáles fueros las garantías que se dieron para que los partidos políticos pudiesen entrar en la esfera pública. La hipótesis que aquí se sostiene es que la reforma de 1910 puede verse como un avance dentro de la estructura institucional colombiana, pues, como se verá más adelante, no representó la imposición de la fuerza de un partido político, sino un verdadero acuerdo dentro de las estructuras de partidos del momento. Por supuesto, como lo señala Duque (2011, p. 
189), se mantienen unas constantes tales como el presidencialismo, el bicameralismo, el origen mixto del Congreso de la República, pero de la misma manera se ratifican y se incorporan otras reglas, tales como la definición confesional del Estado, la moderación del presidencialismo, los cambios electorales, el control de constitucionalidad, así como la ampliación de derechos como garantías para los ciudadanos.

Duque manifiesta, entonces, que la reforma de 1910 se presentó bajo el esquema de la negociación refrendada, ${ }^{1}$ contrario a lo sucedido con la Constitución de 1886 que se puede considerar una situación de fuerza suficiente, es decir, una situación donde un movimiento político tiene la capacidad de imponer un solo criterio. En este sentido, Rafael Núñez y la postura de la Regeneración lograron excluir a los liberales radicales que los dejó por fuera del debate político (Duque, 2011, pp. 187, 188).

Dentro del esquema que se ha presentado sobre el concepto de consenso, y con el fin de poder organizar los temas y debates en la reforma de 1910, se van a tener en cuenta tres ideologías que van a variar de acuerdo con las pretensiones que cada una busca, que siguiendo el modelo presentado por Gargarella (2005), se pueden resumir así: la ideología conservadora que en lo institucional (parte orgánica de la Constitución) pretende concentrar el poder y con este objetivo fortalecer especialmente la autoridad del Ejecutivo. En cuanto a la parte dogmática, para la ideología conservadora, los derechos comparten concepciones de lo moralmente "bueno" (en general extendidos a criterios religiosos). La ideología liberal busca, en lo institucional, una división de poderes basada en un equilibrio que propenda a evitar tanto la concentración de poder como su antítesis la anarquía, y en cuanto a la parte dogmática procura se garanticen los derechos y libertades individuales. Finalmente, la ideología radical propende, en lo institucional, a la idea de robustecer la ciudadanía, otorgándole mayor poder al Congreso, y en cuanto a la protección de derechos, presupone que estos deberían ser dejados a los reclamos y las necesidades de las mayorías (Gargarella, 2005, pp. 2, 3).

Con el fin de establecer los consensos y disensos presentes en la reforma de 1910, las ideologías serán analizadas por medio de los diferentes cambios que se presentaron respecto de 1) lo que establecía la Constitución de 1886,2 ) las posturas que se tomaron durante los debates (foro público) y 3) para finalmente establecer qué quedó y entrar a concluir cuál es la tendencia ideológica que tiene el Acto Legislativo o3 de 1910.

Los cambios que se dieron con el Acto Legislativo 03 de 1910 serán divididos en dos partes. Por un lado, los que tienen que ver con la parte orgánica de la Constitución, ${ }^{2}$ teniendo cuenta los siguientes criterios: 1) facultades del presidente, 2) independencia judicial y 3) organización territorial. Por otro, para entrar a determinar los cambios

\footnotetext{
${ }^{1}$ Que en este texto se pretende llamar consenso.

${ }^{2}$ Es decir los que tienen que ver con el diseño institucional del Estado.
} 
en la parte dogmática de la Constitución ${ }^{3}$ de 1886, se tendrán en cuenta los siguientes criterios: 1) derechos individuales/civiles y 2) pena de muerte. Estos criterios son seleccionados, porque fueron a los que la Asamblea Nacional Constituyente de 1910 les prestó mayor atención, y en un sentido más general, los que de manera sustancial produjeron los principales cambios a la Constitución de 1886.

El texto tendrá la siguiente estructura formal. En primer lugar, se presentará una aproximación histórica de la reforma de 1910, con el fin de dar cuenta del contexto que se venía presentando. En segundo lugar, se establecerá la manera en que las ideologías liberal, radical y conservadora varían, tras lo cual se determinarán los cambios que institucionalmente se presentaron en la Constitución de 1886 (parte orgánica de la Constitución). Posteriormente, se mostrará cómo las ideologías varían para determinar los cambios que sufrió la Constitución de 1886 en la garantía de derechos (parte dogmática). Por último, se presentarán algunas conclusiones en las que se analizarán el porqué de los cambios ideológicos.

Para los propósitos hasta aquí señalados, se hace uso de fuentes primarias ${ }^{4} \mathrm{y}$ secundarias. La información será aplicada, con el fin de establecer qué cambios sustanciales se produjeron en cuanto a la estructura del Estado, en la transición de la Constitución de 1886 a la reforma de 1910.

\section{Aproximación histórica a la reforma constitucional de 1910}

Con la Constitución de 1886, se había dado fin al proceso federal que se estaba consolidando desde 1851 (Gilmore, 1995). La guerra civil que en ese momento libraban los liberales radicales y conservadores condujo a la imposición de un proyecto político por parte de los vencedores (en este caso los conservadores), pues se implementaron nuevas reglas de juego para poder modificar la Constitución de 1863. De esta manera, Rafael Núñez logra consolidar un proyecto político-administrativo a través de la Constitución de 1886 que pretendía darle legitimación otorgándoles mayor participación a los delegados de los municipios, los cuales serían elegidos por el poder central. No obstante, esta ampliación en la participación política era meramente nominal, pues, como lo señala Restrepo Piedrahíta,

desgraciadamente en esas municipalidades no había intervenido para nada el sufragio popular, sino que todas ellas estaban constituidas por nombramientos procedentes del poder ejecutivo, de manera que los Concejos Municipales, así como los jefes civiles y militares, y el Consejo de Delegatarios, no representaban sino la voluntad del presidente de la república. (1979, p. 110)

\footnotetext{
${ }^{3}$ Es decir los que tienen que ver con la protección de derechos.

${ }^{4}$ Principalmente, los anales de la Asamblea Nacional Constituyente, los artículos constitucionales de 1886 y los artículos de la reforma de 1910.
} 
Con la influencia de este esquema, se reforzó el presidencialismo y el centralismo, además de configurar un sistema electoral perverso que excluía las aspiraciones de los liberales. Después de una gran disputa por el poder, con el paso de dos guerras civiles y un golpe de Estado, asumiría la dirección del país Rafael Reyes, quien

subió al poder bajo los lemas de paz y concordia y menos política y más administración, conformó un gabinete de unión nacional y planteó como propósitos fundamentales de su gobierno la pacificación del país, la reestructuración económica, el desarrollo de las vías de comunicación y el fortalecimiento de la explotación de los recursos naturales. Indudablemente, sobre la propuesta del gobierno de Reyes pesaban los efectos que a nivel político, económico y social habían dejado la guerra de los mil días y la separación de Panamá, además de una profunda debilidad administrativa del Estado, el estancamiento de la producción, el atraso en materia de vías de comunicación y transporte, la grave depreciación del papel moneda y el surgimiento de tendencias separatistas en varias regiones del país. (Quinche, 2011 p. 57)

En estas circunstancias, Reyes presentaría el Proyecto de Acto Reformatorio de la Constitución sobre División General del Territorio, el cual sería aprobado mediante Acto Legislativo 03 de 1905. Lo que pretendía Reyes era dividir varios de los departamentos, para lo cual fue necesario

que los departamentos fueran despojados de sus atribuciones en materia de inversiones extrajeras, inmigración y construcción de vías férreas; las asambleas departamentales fueron sustituidas por consejos administrativos, y las rentas de los departamentos pasaron a manos de la hacienda nacional. Adicionalmente a toda la potestad que le otorgaba la legislación, Reyes podía recurrir a la Ley de alta Policía Nacional, la cual contemplaba destituciones, arrestos y confinamientos a quienes pasaran por alto los dictámenes del gobierno y de la Asamblea, o a quienes instigaran y protagonizaran hechos considerados como alteraciones del orden público. (Vélez citado por Quinche, 2010, p. 61)

El proyecto de Rafael Reyes terminaría en 1908 cuando definitivamente liquida las provincias existentes y sanciona la división territorial del país en treinta y cuatro departamentos, con lo cual regresó a un sistema semejante al que se había implementado con la que ha sido, quizá, la Constitución más conservadora que ha tenido Colombia, es decir, la Constitución de la Nueva Granada de 1843.

La cantidad de transformaciones administrativas y el debate que se llevaba a cabo por la independencia de Panamá conducirían una vez más a una crisis política e institucional que llevaría al Gobierno de Reyes a su final, y con este el restablecimiento del Congreso. Y así se le otorga el poder, primero, a Jorge Holguín (quien contaba con una 
fuerte oposición partidista) y, finalmente, a Ramón González Valencia. Después de estos sucesos de cambios del poder, el 18 de agosto de 1909 los representantes Nicolás Esguerra e Idelfonso Díaz del Castillo presentaron a consideración del Senado un proyecto de ley, cuyo objeto era la recomposición de la división territorial de 1904, que tuvo éxito cuando Ramón González Valencia sancionó la Ley 65 de 1909 sobre división territorial.

Con todos estos cambios político-administrativos, realizados más por una imposición de fuerza (la concepción de una ideología conservadora), pues se restringiría la democracia y los partidos que podían hacer parte de la nueva Asamblea Constituyente, la reforma de 1910 parece convertirse en un proceso completamente inverso, pues plantea un contexto de discusión política, donde el partido denominado Unión Republicana trataría de establecer nuevas convenciones sobre la estructura del Estado colombiano. ${ }^{5}$

\section{Reformas de carácter institucional: hacia una nueva estructura estatal}

El proceso de consolidación de la reforma de 1910 abrió el camino para que hubiera un consenso o negociación refrendada, pues existieron ciertos acuerdos entre los partidos políticos (Liberal, Conservador y la Unión Republicana) que se concentraron en establecer una serie de procedimientos que brindarían un nuevo espacio para la conformación del Estado de derecho. Dicho espacio de confrontación sería ideológico y no se presentaría entre guerras, como lo fue la consolidación de las Cartas de 1863 y de 1886. El proyecto, por supuesto, no fue fácil de consolidar, ya que se presentaron algunos brotes de distención (Correa, 1996, p. 139, 140). No obstante, se llevarían a cabo cambios significativos, pues la elección de Carlos E. Restrepo (1910-1914) traería un ambiente político más incluyente, pues durante su gobierno se ratificaría el Acto Legislativo 03 de 1910, con el cual se lograrían algunos avances en la estructura institucional del Estado, tales como la restricción de poderes absolutos al presidente, una mejor representación política (electoralmente) y consagraría la excepción pública de inconstitucionalidad.

Ahora bien, en este acápite, se pretende demostrar que los tres cambios: facultades del presidente, independencia judicial y organización territorial, pueden variar o mantenerse constantes, de acuerdo con el consenso que se logre entre la disputa de las tres

\footnotetext{
${ }^{5}$ De acuerdo con Eduardo Rodríguez Piñeres (1914), y para contextualizar a los actores (aunque se advierte que para este trabajo se tuvieron en cuenta más los argumentos ideológicos) dentro del seno de la Asamblea Nacional Constituyente, la alienación fue más o menos la siguiente: "Uno, formado por los diputados conservadores ultras Luis A. Mesa, Gabriel Rosas, Jesús Perilla V. y Benjamín Guerrero [...]; otro, de conservadores reposados que no habían sido reyistas y que aceptaban la introducción de reformas al Estatuto, como Pedro Nel Ospina, Restrepo Sáenz, Holguín y Caro y Carreño; otro, el de liberales díscolos como Lombana Barreneche, Wallis y Espinosa y, finalmente, el de la Unión Republicana integrada por lo más granado del liberalismo doctrinario y del conservatismo histórico, cuyas cabezas más visibles eran Esguerra y Herrera, del primero, y Quintero Calderón y Ferrero, del segundo" (Ríos, 1991).
} 
ideologías. Por supuesto, como se advirtió al principio, un consenso implica ganancias y pérdidas para una u otra ideología.

\section{Facultades del presidente}

Después de que la Constitución de los Estados Unidos de Colombia de 1863 había logrado restringir los poderes del entonces presidente Tomás Cipriano de Mosquera, con una tendencia de tintes liberal-radical, la implementación de la Constitución de 1886 pretendía imponer de nuevo un sistema centralista que concentrara los poderes en la rama ejecutiva. Este objetivo se conseguiría fortaleciendo las facultades otorgadas al presidente de la república. ${ }^{6}$ Entre los poderes que se le atribuyen, se destacan la potestad de tener dos periodos presidenciales de seis años y de ser reelegido discontinuamente (artículo 114), además de tener el control sobre la elección de ministros, gobernadores, alcaldes y magistrados de la Corte Suprema de Justicia. Además, se le otorgaron facultades extraordinarias establecidas en el articulo 121 de la Constitución, lo cual le permitía suspender, en muchas ocasiones, garantías constitucionales (Barreto, 2011, pp. 199 y ss.). De hecho, el artículo 28 disponía:

Aun en tiempo de paz, pero habiendo graves motivos para temer perturbación del orden público, sean aprehendidas y retenidas, de orden del Gobierno y previo dictamen de los Ministros, las personas contra quienes haya graves indicios de que atentan contra la paz pública.

Esta cláusula le permitía, incluso, hacer uso de la fuerza por una "tentativa" de alteración al orden público. De la misma manera, el control de constitucionalidad de normas era restringido a la objeción que pudiera hacer solo el presidente.

Durante los debates de la Asamblea Constituyente de 1910, representantes del Partido Conservador defendían la concentración del poder en el Ejecutivo. Así, por ejemplo, el diputado Arbeláez señalaba:

Creo un deber emitir concepto con relación a la vigencia del artículo 121 de nuestra Constitución. Por este artículo se pusieron en manos del presidente de la República los medios necesarios para contrarrestar las revoluciones: merced a él, si conservamos su vigencia, se podrá cimentar la paz, único medio para entrar de lleno en el camino del progreso y de la civilización. (Anales de la Asamblea Nacional Constituyente, 7 julio 1910)

Es claro que la ideología conservadora buscaba que el poder ejecutivo no perdiera facultades y fuera el que "guiara” la senda por el camino hacia la protección de

${ }^{6}$ Implementadas en el título XI de la Constitución Política de la República de Colombia de 1886. 
derechos y la paz. No obstante, y a pesar de los argumentos expuestos por la ideología conservadora, la ideología liberal lograría ganar esta apuesta, pues, finalmente, se modificó el artículo 121 de la Constitución de 1886 y se dispuso en artículo 32 del Acto Legislativo o3 de 1910 que "el Gobierno no puede derogar las leyes por medio de los expresados decretos. Sus facultades se limitan a la suspensión de los que sean incompatibles con el Estado de Sitio”.

Ahora bien, mientras la Constitución de 1886 disponía en el artículo 114 que el presidente sería elegido por asambleas departamentales para un periodo de seis años, la reforma de 1910 en el artículo 25 le reducía el periodo a cuatro años, sin derecho a reelección inmediata. Además, dicho artículo establecía que será elegido por los ciudadanos que tienen derecho a sufragar (en este caso solo por quienes supieran leer y escribir o tuvieran renta de $\$ 300$ al año o propiedad de $\$ 1000$ ), extendiendo las facultades para que hubiera una mayor representación democrática (Anales de la Asamblea Nacional Constituyente, 15 julio 1909).

En este orden de ideas, la ideología radical se alinearía con la posición liberal en algunos sentidos, pues se logró que hubiera ciertos controles por parte del Congreso. Por ejemplo, se le quitó la facultad al presidente de hacer convenios internacionales, no sujetos a la aprobación del Congreso, además de establecer la responsabilidad de este por todas las violaciones a la Constitución y las leyes.

De la misma manera, la Constitución de 1886 solo hacía responsable al presidente por lo siguiente: 1) actos de violencia o coacción en elecciones; 2) actos que impidan la reunión constitucional de las cámaras legislativas o estorben a estas o a las demás corporaciones o autoridades públicas establecidas en la Constitución para el ejercicio de funciones públicas; y 3) delitos de alta traición. En contraposición a estas normas, el Acto Legislativo 03 de 1910 en el artículo 29 lo hace responsable por los actos o las omisiones que violen los procesos constitucionales o las leyes, con lo cual amplió su grado de responsabilidad de manera considerable.

Teniendo en cuenta el anterior análisis, se puede señalar que la ideología conservadora se ve limitada, pues, mientras la Constitución de 1886 había mantenido una constante presidencialista, casi sin responsabilidades, la reforma de 1910 logra una mejor división de poderes y algunos controles por parte del Congreso (tabla 1).

Tabla 1. Resumen del argumento principal por ideología en la Asamblea Nacional Constituyente

\begin{tabular}{|l|l|}
\hline \multicolumn{1}{|c|}{ Ideología } & \multicolumn{1}{c|}{ Argumentos } \\
\hline Liberal & Desconcentración del poder \\
\hline Conservadora & El presidente debe velar por la salvaguarda del orden público \\
\hline Radical & El Congreso debe tener control sobre el presidente \\
\hline
\end{tabular}

Fuente: elaboración propia 


\section{Independencia judicial}

El 15 de mayo de 1910 el diputado por Antioquia, Nicolás Esguerra, presentaría un proyecto de reforma constitucional, cuya pretensión era que la guarda de la Constitución quedara en cabeza de la Corte Suprema de Justicia. Lo que se pretendía era una nueva forma de organización institucional, pues, con la Constitución Política de 1886, el nombramiento de magistrados se encontraba en cabeza del Ejecutivo. ${ }^{7}$ Además, como lo señala Rodríguez Peñaranda (2010):

El nuevo sistema de control de constitucionalidad afinó la tradicional división de las ramas del poder público ideada por Locke y Montesquieu, dando lugar a un reacomodamiento de los poderes y en especial del poder e independencia de la rama judicial, ajustada a la preservación de la democracia en un régimen presidencial.

Con esta nueva división de poderes, se conseguiría romper, además, con la tradición europea de revisión político-judicial en cabeza del legislativo y se abriría campo a una visión más amplia de control de poderes.

En el seno de la Asamblea Nacional Constituyente, los representantes del Partido Conservador señalaban sobre este punto:

Como argumento principal a favor del artículo que dice que al hacer el Poder Ejecutivo los nombramientos de magistrados de la Corte, esta elección no se hace con entera libertad, porque está sujeta a intrigas y nexos entre el nombrado y la entidad que lo designa. Pero si el nombramiento se hace por el Congreso se corre el mismo peligro, porque supongamos que el Poder Legislativo dicta una Ley que va a conocimiento de la Corte Suprema, y naturalmente esta entidad la declarará constitucional en acatamiento al Cuerpo que la eligió. ¿QQuién debe juzgarlo? La Corte Suprema; mientras al Presidente lo juzga el Senado. (Anales de la Asamblea Nacional Constituyente, 30 junio 1910)

El argumento, por supuesto, pretendía retener las facultades de nombramiento de los magistrados en el Ejecutivo, argumentando que se presentarían las mismas dificultades de responsabilidad que si se transfieren dichas competencias al poder legislativo. En contraste con este argumento, el diputado Espinosa, con una propuesta de tintes radicales, proponía: “Solamente las Asambleas Departamentales y el Cuerpo Legislativo

\footnotetext{
${ }^{7}$ El Acto Legislativo 03 de 1910 en su artículo 41 señalaba: "A la Corte Suprema se le confía la guarda de la integridad de la Constitución. En consecuencia, además de las facultades que le confieren ésta y las leyes, tendrá la siguiente: Decidir definitivamente sobre la exequibilidad de los Actos Legislativos que hayan sido objetados como inconstitucionales por el Gobierno, o sobre todas las leyes o decretos acusados ante ella por cualquier ciudadano como inconstitucionales, previa audiencia del Procurador General de la Nación".
} 
son los que tienen derecho a intervenir en el nombramiento de la Corte Suprema. Así resultarían elegidos estos por el voto popular indirecto" (Anales de la Asamblea Nacional Constituyente, 30 junio 1910). En este mismo sentido, Espinosa señalaba:

\begin{abstract}
Yo no veo aceptable la modificación propuesta por el honorable diputado Pérez, porque no veo la razón para que el presidente de la República intervenga en el nombramiento de magistrados de la Corte Suprema de Justicia. Al contrario, son palpables y muy conocidos los inconvenientes que entraña tal procedimiento, que hace que hasta ciertos puntos dependientes de la voluntad del Presidente a los magistrados de la Corte Suprema, quienes en ese caso le deba a él el puesto que ocupa. (Anales de la Asamblea Nacional Constituyente, 30 junio 1910)
\end{abstract}

Ahora bien, en relación con la independencia del poder judicial, se puede determinar:

En este contexto, las constituciones políticas continuaban encarnando el fetiche del poder, el vae victis de los bárbaros. Esta dinámica del diecinueve fue modificada por un movimiento político, que pese a su corta vida, produjo uno de los más importantes ajustes al sistema político colombiano; hablamos de la Unión Republicana, que bajo el liderazgo del antioqueño Carlos Eugenio Restrepo, el apoyo de Nicolás Esguerra y Eduardo Rodríguez Piñeres, dieron forma a un nueva ética de lo público en el que el poder judicial se convertiría en el principal bastión de defensa de los derechos y la democracia. (Rodríguez Peñaranda, 2010)

Los debates tendrían precisamente como centro la cuestión de si el control de constitucionalidad debía llevarse a cabo por el poder legislativo o judicial. Con estos precedentes, se conseguiría que, finalmente, el control de constitucionalidad quede en cabeza de la Corte Suprema de Justicia y se implemente un control de constitucionalidad público, quizá el primero en el mundo (Cajas y López, 2008). ${ }^{8}$ El análisis que de aquí se desprende es que la reforma conseguiría por primera vez una independencia judicial, que aproximó el control de constitucionalidad a la sociedad civil y, con esto, la ideología liberal logró imponer otro punto a su favor. Por su parte, la ideología conservadora pierde poder al permitir que se le quite esta facultad al presidente. De la misma manera, la ideología radical no consigue que esta facultad pase al seno del Congreso, y dicha potestad nunca les fue dada en ninguna de las dos normas (tabla 2).

${ }^{8}$ Venezuela también implementaría una acción popular de constitucionalidad, mediante la Constitución de Valencia de 1858. 
Tabla 2. Resumen del argumento principal por ideología en la Asamblea Nacional Constituyente

\begin{tabular}{|l|l|}
\hline \multicolumn{1}{|c|}{ Ideología } & \multicolumn{1}{c|}{ Argumento } \\
\hline Liberal & Pretende una división de poderes y una justicia independiente \\
\hline Radical & El control de las normas constitucionales la debería hacer el Congreso \\
\hline Conservadora & El presidente debería ser el protector de la Constitución \\
\hline
\end{tabular}

Fuente: elaboración propia

\section{Organización territorial}

La Constitución de 1863 había fijado un régimen completamente federal, con un gran impulso de los liberales y radicales, que pretendían darles mayor independencia a las provincias. El panorama político cambiaría, pues dos hechos marcarían la historia de Colombia y con estos el giro del péndulo hacia el centralismo. El primero es la Constitución de 1886 y, con esta, un proyecto centralista; el segundo es la Administración de Reyes, quien, con la Ley 1 de 1908, ${ }^{9}$ pretendía tener control sobre el mapa político administrativo de Colombia, y lo conseguiría, pues quedarían bajo su potestad facultades tales como modificar límites territoriales y establecer nuevas divisiones.

La Asamblea Constituyente de 1905 les daba visto bueno a las pretensiones de Reyes señalando: "Solamente la experiencia podrá decir qué rectificaciones necesita la demarcación material de territorio que se proyecta; por ello hemos creído conveniente facilitar dichas rectificaciones dando autorización al gobierno para que las haga, si de ello hubiere necesidad" (Asamblea Nacional Constituyente y Legislativa, Informe de la Comisión que estudió el Proyecto de Ley sobre División Territorial, 1905).

Con estos precedentes, la reforma de 1910 buscaba darle una nueva organización territorial al país y

en efecto, el 18 de agosto de 1909 los representantes Nicolás Esguerra e Idelfonso Díaz del Castillo presentaron a consideración del Senado un proyecto de ley cuyo objeto era la recomposición de la división territorial de 1904 y el restablecimiento de las condiciones establecidas por la Constitución de 1886 para la creación de nuevos departamentos, todo con el fin manifiesto de dar solución rápida y definitiva a los problemas administrativos y jurisdiccionales que se habían producido en los últimos años en función de la serie de reformas impuestas sobre el mapa político colombiano. (Quinche, 2001, p. 73)

Ahora bien, una vez desestimada la solicitud hecha por parte del diputado Bonilla de que se suspendieran los debates sobre ordenamiento territorial hasta que no se

\footnotetext{
${ }^{9}$ Revisado y, por supuesto, aprobado rápidamente por la Asamblea Constitucional que el mismo Reyes había convocado.
} 
presentara informe por parte de la Comisión de División Territorial, los debates continuarían, y en una defensa por el cambio administrativo-territorial, se indicaba:

En materia de división territorial administrativa se presentan dos faces diferentes: ó se hace en la Constitución, ó se deja a la ley. Lo primero lo hizo una reforma constitucional del quinquenio. Lo que dispuso la Constitución de 1886 obedeció no a un procedimiento científico, sino a una contemporización con el regionalismo imperante entonces, por obra de la federación. (Anales de la Asamblea Nacional Constituyente, 15 junio 1910)

Y refiriéndose a los inconvenientes de la reforma sobre el aumento del número de departamentos señala: "La multiplicación de estos tiene graves inconvenientes; uno de ellos el aumento de los cargos públicos sobre los ciudadanos, y otro la menor capacidad de esas entidades para su desarrollo (Anales de la Asamblea Nacional Constituyente, 15 junio 1910).

En el proyecto de reforma, los diputados Holguín y Miguel Antonio Caro (de ideología conservadora) determinaban la necesidad de establecer el voto de las dos terceras partes de ambas cámaras para la aprobación de la creación de un nuevo departamento. ${ }^{10}$ Contra esta postura, el diputado Salazar indicaba:

No señores: apenas se trata de la división administrativa del territorio sometido al régimen central de una República unitaria, cuyas instituciones no permiten a los Distritos vender un pedazo de tierra sin el consentimiento de los altos poderes que residen en Bogotá. Bajo este régimen solo podemos procurar algún amago de autonomía municipal [...] Aunque siempre acertad en sus discursos el honorable diputado Holguin y Caro, y con gran caudal de argumentos convincentes en esta ocasión me da lugar a reparos. Estimo necesario suprimir de este artículo la condición exigida de que haya que contar con las dos terceras partes de la votación de ambas Cámaras la ley que disponga la creación de nuevos Departamentos, porque de esa manera se imposibilita ó se hace mas difícil lo que hemos querido facilitar. (Anales de la Asamblea Nacional Constituyente, 15 junio 1910)

Por su parte, algunos representantes, como Lombana Barrera, sostenían que era mejor dejar sentando en la reforma cuestiones de ordenamiento territorial, y en el caso concreto de creación de departamentos, deberían ser establecidos de acuerdo con el número de habitantes (150 00o). Agregaba, además, Lombana, que debería ser la Corte

${ }^{10}$ Tratando de aplicar una cláusula pétrea para la creación de nuevos departamentos, pues conseguir este porcentaje era fácticamente imposible, como lo evidencian las posturas que se detallan en este texto. 
Suprema la que determinara la creación de un departamento (Anales de la Asamblea Nacional Constituyente, 11 junio 1910).

Finalmente, se establecerían tres requisitos principales para la creación de municipios: 1) la solicitud por las tres cuartas partes de consejeros de una comarca, 2) un renta determinada y 3) que una ley lo aprobara. ${ }^{11}$

Con estos argumentos, se volvería a mover el mapa político-administrativo de Colombia, pues el ordenamiento territorial se tornaba más flexible para que se formaran nuevos departamentos y tuvieran mayor independencia financiera (Asamblea Nacional Constituyente, 9 junio 1910).

La conclusión que de aquí se desprende es que jamás se pudo volver al federalismo de las décadas de 1950 y 1960. Sin embargo, sí se logra con el Acto Legislativo 03 de 1910 una mayor descentralización administrativa y financiera para el territorio nacional que la que había impuesto la Constitución de 1886.

El esquema que se presenta es un triunfo de los liberales que pretendían la desconcentración del poder central y una ganancia a medias para los radicales, para quienes la federación era un constante sueño, en el que los estados federados pudieran tener elecciones y mayor representatividad para el Congreso (tabla 3).

\section{Tabla 3. Resumen del argumento principal por ideología en la Asamblea Nacional Constituyente}

\begin{tabular}{|l|l|}
\hline \multicolumn{1}{|c|}{ Ideología } & \multicolumn{1}{c|}{ Argumento } \\
\hline Liberal & $\begin{array}{l}\text { La descentralización contribuye a la autonomía administrativa de los } \\
\text { departamentos, los cuales deben darse sus propias directrices. }\end{array}$ \\
\hline Radical & $\begin{array}{l}\text { A pesar de que no se logra una representación tan amplia como la } \\
\text { federación, el Acto Legislativo } 03 \text { sí consigue mayor representación de } \\
\text { los entes territoriales. }\end{array}$ \\
\hline Conservadora & El poder central servía para un mejor control del país. \\
\hline
\end{tabular}

Fuente: elaboración propia

\section{Parte dogmática de la Constitución}

La Constitución de 1886 en su artículo 52 establecía una cláusula que señalaba: "Las disposiciones del presente Título se incorporarán en el Código Civil como Título preliminar, y no podrán ser alteradas sino por acto reformatorio de la Constitución”. Como afirma Valencia (2010, p. 64), el artículo parece no ser claro. Sin embargo, lo que establecía era que los derechos que estaban en la Constitución deberían adherirse

\footnotetext{
${ }^{11}$ Artículo 2, Acto Legislativo 03 de 1910: "El territorio nacional se dividirá en Departamentos y éstos en Municipios o Distritos Municipales. La ley puede decretar la formación de nuevos Departamentos, desmembrando los existentes, cuando haya sido solicitada por las tres cuartas partes de los Consejeros Municipales de la comarca que ha de formar el Departamento, y siempre que se llenen estas condiciones: que el nuevo departamento tenga al menos 250.000 habitantes y 250.000 oro de renta anual no menor de $\$ 250.000$; y que la creación sea decretada por una ley aprobada por dos legislaturas anuales sucesivas".
} 
o eran una extensión de los del Código Civil que dejaban los derechos y principios fundamentales por fuera de ella.

En este espacio, me concentraré en mostrar dos de las tendencias más debatidas durante la Asamblea Nacional Constituyente. La primera es la relación de derechos como el voto y el sistema electoral con la libertad religiosa. La libertad religiosa entendida en este caso como derecho de la Iglesia católica para acceder a la participación política y no ser relegada de ella. ${ }^{12}$ El segundo derecho o tendencia en el que se enfocará este análisis es la pena de muerte.

\section{Derechos y relación Iglesia-Estado}

Después de que se implementara por parte de Reyes la Ley 61 de 1888, conocida como la ley de los caballos, por el fuerte trato que se le daba a la sociedad civil, los ciudadanos se encontraban limitados, pues todo acto que "atentara" contra el orden público podría ser reprimido por la fuerza.

La Unión Republicana se encargaría, en este sentido,

principalmente en garantizar las libertades públicas, que acababan de sufrir tan grande detrimento, y comenzó a restablecerse la vigencia de la Ley 51 de 1898 sobre libertad de prensa. Lo mismo ocurriría en la Asamblea Nacional Constituyente de 1910; estos constituyentes llevarían a cabo las discusiones sobre instituciones jurídicas que les garantizaran a los ciudadanos el respeto de los derechos constitucionales. (Maya, 2012, p. 125)

La Asamblea parecía dar un giro hacia la mayor participación política y con ella a ciertas libertades individuales que son necesarias para que una democracia funcione. Ya se había advertido, incluso, que la acción pública de constitucionalidad no solo permitió una justicia independiente alejada del poder ejecutivo, sino que garantizó en cierta medida que se respetaran ciertos derechos individuales, y como lo señala Maya:

Los derechos dejaron de tener nivel legal, garantizando así la protección de éstos sin necesidad de que el Legislativo o el Ejecutivo expidieran normas con tal fin. $\mathrm{Al}$ reconocer la libertad de prensa como un derecho con rango superior a la ley, los presidentes y legisladores tenían un límite constitucional que les impediría, al menos jurídicamente, la promulgación de leyes encaminadas a la restricción de este derecho. Este cambio en la percepción del Legislador y del Juez representó una ruptura: al menos formalmente, el Legislador dejó de ser concebido como un poder virtuoso y el Juez empezó a ser posicionado como

${ }^{12}$ Se realiza este acercamiento por índoles metodológicas y de espacio en el texto, posteriormente se pretende profundizar y separarlas. 
un poder con la facultad de ejercer control constitucional, mediante la acción pública de inconstitucionalidad sobre las leyes. Esto quiere decir que desde ese momento hasta la actualidad los jueces deben proteger las garantías constitucionales y no aplicar leyes inconstitucionales. (p. 127)

Ahora bien, de la misma manera, el acto legislativo parece abrir un nuevo campo para los derechos de participación ciudadana, pues los liberales sostenían:

Nosotros los liberales estamos en la obligación de defender los derechos del pueblo, aún cuando lo contrario pudiera ser ventajoso para los intereses del partido en ciertos momentos. Si las elecciones populares no han dado resultados benéficos, el mal está en la manera como ellas se hacen. Para que la elección popular sea expresión verdadera de la voluntad del pueblo, lo que se necesita es que la Constitución y la ley establezcan preceptos que garanticen la efectividad del sufragio. (Anales Asamblea Nacional Constituyente, 2 julio 1910)

Respecto de las reformas que se pretenden a los derechos de participación y religión, se puede notar que no hubo un total rechazo a la religión, pues se establecía:

La religión es el elemento necesario de la vida del espíritu: podemos decir que es la savia moral de las inteligencias, la fuerza más poderosa en la conciencia de los hombres y de los pueblos. Desgraciados aquellos que pierden la fe, porque privados de tan necesario elemento de vida. (Anales Asamblea Nacional Constituyente, 25 noviembre 1909)

Acá podemos encontrar una tensión interesante, pues, a pesar de la apertura hacia nuevos derechos y la libertad de prensa, se mantiene una constante en la relación IglesiaEstado, ya que no existió la apuesta que caracteriza la ideología liberal de separar estas dos instituciones, como sí se pensó en 1853 y que se concretaría en la Constitución de 1863 (Gilmore, 1995, p. 164). En los debates de la Asamblea Constituyente, parecía haber un cierto consenso sobre la importancia de tener la religión católica como pilar de la moral política (tabla 4).

Tabla 4. Resumen del argumento principal por ideología en la Asamblea Nacional Constituyente

\begin{tabular}{|l|l|}
\hline Ideología & Argumento Nacional \\
\hline Liberal & Mayores derechos electorales y participación de la sociedad civil \\
\hline Radical & Mayor representación de mayorías \\
\hline Conservadora & Religión: moral católica continúa como constante \\
\hline
\end{tabular}

Fuente: elaboración propia 


\section{Pena de muerte}

La Constitución de 1886 establecía la pena de muerte en el artículo $29^{13}$ y se llevarían a cabo fuertes debates por la conveniencia o no de suprimirla. En este sentido, el diputado Holguín indicaba:

La pena de muerte no está prohibida por la moral cristiana ni por la ley eterna. La vida es un derecho y Dios no ha dado al hombre derecho alguno de forma ilimitada, porque todo derecho tiene necesariamente un término y todo derecho termina donde principia el derecho ajeno, el derecho de los demás hombres o el derecho de la sociedad. [...] Siendo esto así, nadie podrá negar que la vida de un individuo que pone en peligro la existencia de la sociedad, debe ceder ante el derecho de la sociedad a existir ordenadamente. (Anales de la Asamblea Nacional Constituyente, 24 junio 1910)

Contra este argumento, el diputado Lombana Barreche señalaría que son los postulados de la Iglesia y su moral los que han permitido que se imponga la pena de muerte en muchas circunstancias. Sin embargo, en el ámbito penal,

de cada país, la cuestión es muy distinta. Del mismo modo que la muerte del agresor injusto no se legitima sino cuando la necesidad personal la impone, del propio modo la pena capital no puede, no debe figurar en la legislación común de un país sino cuando ella es necesaria. Pero aquí cabe preguntar: ¿y cuándo es ella necesaria? Pero a esa pregunta no puede contestarse con una sola palabra, porque ella depende de muchas circunstancias. (Anales de la Asamblea Nacional Constituyente, 24 junio 1910)

Posteriormente, el argumento de Lombana sería que la pena de muerte ha disminuido la delincuencia en Colombia, a pesar de no haber datos científicos. No obstante, para Lombana la potestad de la pena de muerte en estas circunstancias excepcionales estaría a cargo del Código Penal y no de la Constitución.

Después, Olaya Herrera, en representación del Partido Liberal, celebraba la abolición de la pena de muerte como uno de los avances de la condición humana y de la sociedad colombiana misma. El diputado Segovia también defendería la abolición de la pena de muerte, pero sosteniendo que el Estado no tiene derecho a quitarle la vida a una persona, cuando dicho Estado no ha hecho lo necesario para educar a la sociedad

\footnotetext{
13 "Artículo 29. Sólo impondrá el Legislador la pena capital para castigar, en los casos que se definan como más graves, los siguientes delitos, jurídicamente comprobados, a saber: traición a la Patria en guerra extranjera, parricidio, asesinato, incendio, asalto en cuadrilla de malhechores, piratería, y ciertos delitos militares definidos por las leyes del ejército. En ningún tiempo podrá aplicarse la pena capital fuera de los casos en este artículo previstos" (Constitución de Colombia 1886).
} 
(Anales de la Asamblea Nacional Constituyente, 24 junio 1910). Otros diputados, como Restrepo Sáenz, también exponían argumentos liberales, como la posibilidad de que un inocente pueda morir bajo la injusticia de la pena de muerte.

No obstante, y en contraposición a las ideas expuestas, los diputados conservadores señalaban que la pena de muerte era necesaria, pues, en países de alto orden económico, se aplicaba, como el caso de los Estados Unidos y Francia. Otros diputados, como Villegas, con un argumento de tendencia más radical, también estaba de acuerdo con que se impusiera la pena de muerte, pues indicaba que, a pesar de no estar de acuerdo con la pena de muerte particularmente, tenía que entregarse a los dictámenes del pueblo, que, en su gran mayoría, sí estaba de acuerdo con la imposición de la pena de muerte (Anales de la Asamblea Nacional Constituyente, 24 junio 1910).

A pesar de los diferentes argumentos que se daban a favor de la abolición de la pena de muerte entre liberales y conservadores, sí parecía haber un cierto consenso en este punto, que, por supuesto, iba a favor de la ideología liberal que dio como resultado final la abolición de la pena de muerte.

En este sentido, mientras la Constitución de 1886 en el artículo 29 señalaba los casos para la pena de muerte, ${ }^{14}$ la reforma de 1910 prohíbe dicha pena. Se podría hacer el siguiente esquema, entonces, de las posiciones conservadoras, radicales y liberales (tabla 5).

\section{Tabla 5. Resumen del argumento principal por} ideología en la Asamblea Nacional Constituyente

\begin{tabular}{|l|l|}
\hline \multicolumn{1}{|c|}{ Ideología } & \multicolumn{1}{c|}{ Argumento } \\
\hline Liberal & Posición liberal de protección de derechos individuales y progreso civil. \\
\hline Radical & Se debe establecer qué piensa la mayoría de los colombianos. \\
\hline Conservadora & $\begin{array}{l}\text { La pena de muerte debe establecerse como un condicionamiento moral } \\
\text { (religioso). }\end{array}$ \\
\hline
\end{tabular}

Fuente: elaboración propia

\section{Conclusiones}

El análisis presentado pretendía sostener, en primer lugar, la manera en que una ideología puede mostrar un cambio en la estructura del Estado. En este sentido, mientras la Constitución de 1886 tenía una tendencia conservadora, con un Ejecutivo fuerte, un Congreso limitado, una organización territorial centralizada y una justicia atada al poder ejecutivo, el Acto Legislativo 03 de 1910 tiene una tendencia contraria, pues pretende

\footnotetext{
14 "Artículo 29. Sólo impondrá el Legislador la pena capital para castigar, en los casos que se definan como más graves, los siguientes delitos, jurídicamente comprobados, a saber: traición a la Patria en guerra extranjera, parricidio, asesinato, incendio, asalto en cuadrilla de malhechores, piratería, y ciertos delitos militares definidos por las leyes del ejército. En ningún tiempo podrá aplicarse la pena capital fuera de los casos en este artículo previstos" (Constitución de Colombia 1886).
} 
limitar los poderes del Ejecutivo, abrir más espacios a la participación democrática y darle independencia a la rama judicial entregándole, incluso, la custodia de la Constitución.

En este mismo sentido, en cuanto a la protección de derechos, la Constitución de 1886 mostraba una tendencia privatista, y llegó, incluso, a relacionar los derechos constitucionales con los civiles. La reforma de 1910, por su parte, muestra una tendencia más abierta que pretende darle mayores potestades a la sociedad civil y garantizar derechos individuales al prohibir la pena de muerte, además de una mayor participación a la prensa, que garantizaría el derecho de libertad de expresión.

Ahora bien, como bien lo señala Silva, la reforma representó:

Una década (1910-1920) que, por otra parte, conocerá procesos notables de reordenamiento territorial - formación de nuevas unidades territoriales (departamentos)-, procesos que se cumplirán sin enfrentamientos militares, y en parte sin grandes tensiones, por fuera de las que se vivieron en el terreno de la prensa, la opinión pública y el propio Congreso de la República, es decir, en el marco que supone el funcionamiento institucional democrático. (2010, p. 283)

De esta manera, la reforma de 1910 sí logró realizar un cambio respecto de la Constitución de 1886, pues se presentó entre diferentes consensos de partidos e ideologías. ${ }^{15}$ Consenso que implicó, en este caso, una tendencia de ideología liberal.

El análisis metodológico tuvo como referencia fuentes primarias y secundarias, que se consideran representan una postura ideológica. Esto se sustenta en que muchas veces los partidos políticos no siempre coinciden con las ideologías que pretenden representar. En este sentido, con el análisis que presenta Gargarella (2005), se pretendía establecer qué tendencia ideológica (y no de partidos) tenía la Constitución de 1886, en comparación con la reforma de 1910, estableciendo algunos argumentos de transición que lograron finalmente un resultado.

Finalmente, se puede aclarar que, a pesar del rotundo cambio que pareciesen arrojar los resultados, habría que observar con más calma cuáles fueron los cambios reales que se presentaron con la reforma de 1910. Es decir, se sabe que el Acto Legislativo 03 implicó un gran cambio tanto en lo institucional como en la protección de derechos. No obstante, valdría la pena determinar las causas para que posterior a una reforma tan importante como la estudiada no se haya podido consolidar un proyecto político estable en Colombia conduciéndonos a reformas tan grandes, como la de 1936 y la posterior época de la violencia.

${ }^{15}$ Y no por la imposición de un proyecto político, que se da por medio de la suficiente fuerza para imponerlo, como fue el caso de los anteriores proyectos constituciones (Valencia, 2010). 


\section{Referencias}

Acto Legislativo 03 de 1910.

Anales de la Asamblea Nacional Constituyente de 7 de julio de 1910.

Anales de la Asamblea Nacional Constituyente de 11 de junio de 1910.

Anales Asamblea Nacional Constituyente de 24 de junio de 1910.

Anales de la Asamblea Nacional Constituyente de 30 de junio de 1910.

Anales Asamblea Nacional Constituyente de 2 de julio de 1910.

Anales de Asamblea Nacional Constituyente de 15 de julio de 1910.

Anales Asamblea Nacional Constituyente de 25 de noviembre de 1910.

Barreto Rozo, A. (2011). Venturas y desventuras de la Regeneración. Bogotá: Universidad de los Andes.

Calderón, M. T., Restrepo, I. y Posada Carbó, E. (2010). Colombia 1910-2010. Bogotá: Taurus.

Cajas Sarria, M. A. y López Medina, D. E. (2008). El control judicial a la reforma constitucional: Colombia, 1910-2007. Santiago de Cali: Universidad Icesi.

Chinchilla, T. (2010). Concepciones sobre el juez constitucional en la reforma de 1910: una cuestión de confianza. Diálogos de Derecho y Política, 3, 1-16.

Constitución de 1886.

Correa Uribe, F. (1996). Republicanismo y reforma constitucional 1891-1910. Medellín: Universidad de Antioquia.

Diario Neogranadino 1853.

Duque Daza, J. (2011). La reforma constitucional de 1910: constantes institucionales, consensos y nuevas reglas. Papel Político, 16(1), 185-212.

Gargarella, R. (2005). Los fundamentos legales de la desigualdad: el constitucionalismo en América (1776-1860). Madrid: Siglo XXI.

Gilmore, R. L. (1995). El federalismo en Colombia 1810-1858. Bogotá: Universidad Externado de Colombia.

Maya Chaves, M. J. (2012). Discordia, reforma constitucional y excepción de inconstitucionalidad. Revista de Estudios Sociales, 42, 118-128.

Quinche, C. (2011). El Quinquenio de Rafael Reyes y la transformación del mapa políticoadministrativo colombiano. Universidad Nacional de Colombia. 
Rawls, J. (2006). El liberalismo político. Barcelona: Crítica.

Renán, S. (2010). Cultura, cambio social y formas de representación. En M. T. Calderón, I. Restrepo y E. Posada Carbó, Colombia 1910-201O. Bogotá: Taurus.

Restrepo, C. E. (1912a). Estudios constitucionales (I). Revista de la Academia Colombiana de Jurisprudencia, 25.

Restrepo, C. E. (1912b). Estudios constitucionales: jurisdicción política del poder judicial. Revista de la Academia Colombiana de Jurisprudencia, 26.

Restrepo Piedrahíta, C. (1979). Constituciones de la primera república liberal. Bogotá: Universidad Externado de Colombia.

Restrepo Piedrahíta, C. (1992). Las primeras constituciones políticas de Colombia y Venezuela. Ayer, 8, 75-146.

Ríos Peñalosa, G. (1991). Las constituyentes de 1905 y 1910. Revista Credencial Historia, 13. Recuperado de http://www.banrepcultural.org/blaavirtual/revistas/ credencial/enero1991/enero1.htm

Rodríguez Peñaranda, M. L. (21 noviembre 2010). Colombia: 100 años de justicia constitucional y republicana. En Sin Permiso. Recuperado de http://www.sinpermiso. info/textos/colombia-100-aos-de-justicia-constitucional-y-republicana

Rodríguez Piñeres, E. (1914). Relaciones entre los poderes judicial y legislativo. Revista de la Academia Colombiana de Jurisprudencia, 5(51-52).

Rodríguez Piñeres, E. (1916). Relaciones entre los poderes judicial y legislativo. Revista de la Academia Colombiana de Jurisprudencia, 5(51-52).

Rodríguez Piñeres, E. (1956). Hechos y comentarios. Nova et Vetera.

Valencia Villa, H. (2010). Cartas de batalla: una crítica al constitucionalismo colombiano. Bogotá: Panamericana. 
